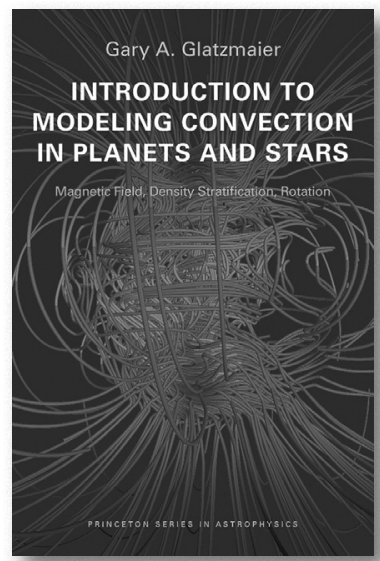

\title{
Introduction to Modeling
}

\section{Convection in Planets and Stars}

Magnetic Field, Density Stratification,

Rotation

\section{Gary A. Glatzmaier}

- Describes how to create codes that simulate the internal dynamics of planets and stars

- Builds on basic concepts and simple methods

- Shows how to improve the efficiency and accuracy of the numerical methods

- Describes more relevant geometries and boundary conditions

- Demonstrates how to incorporate more sophisticated physics

"Glatzmaier's work is synonymous with the cutting edge of research in this field, and his tried-and-true presentation has been perfected over many years of teaching. This is an ideal tutorial for graduate students, and will also be of great interest to senior researchers."

-James M. Stone, Princeton University

Princeton Series in Astrophysics

David N. Spergel, Series Editor

Paper $\$ 65.00$ 978-0-691-14173-2

Cloth $\$ 99.50$ 978-0-691-14172-5

PRINCETON UNIVERSITY PRESS

See our E-Books at press.princeton.edu 


\section{CAMBRIDGE JUUNALS}

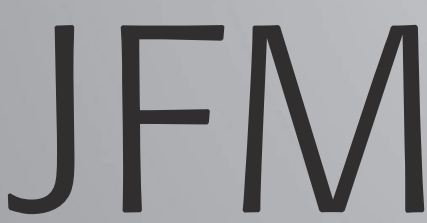

ARCHIVE
Journal of

Fluid Mechanics

Digital Archive 1956-1996

Vital research from the definitive source

The JFM Digital Archive contains every article from the first 40 years of the journal, scanned and digitised to the highest standards.

Please speak to your librarian about gaining access.

\section{journals.cambridge.org/jfm}

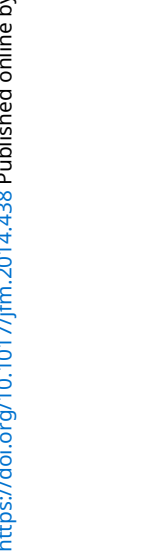

国堛 CAMBRIDGE 


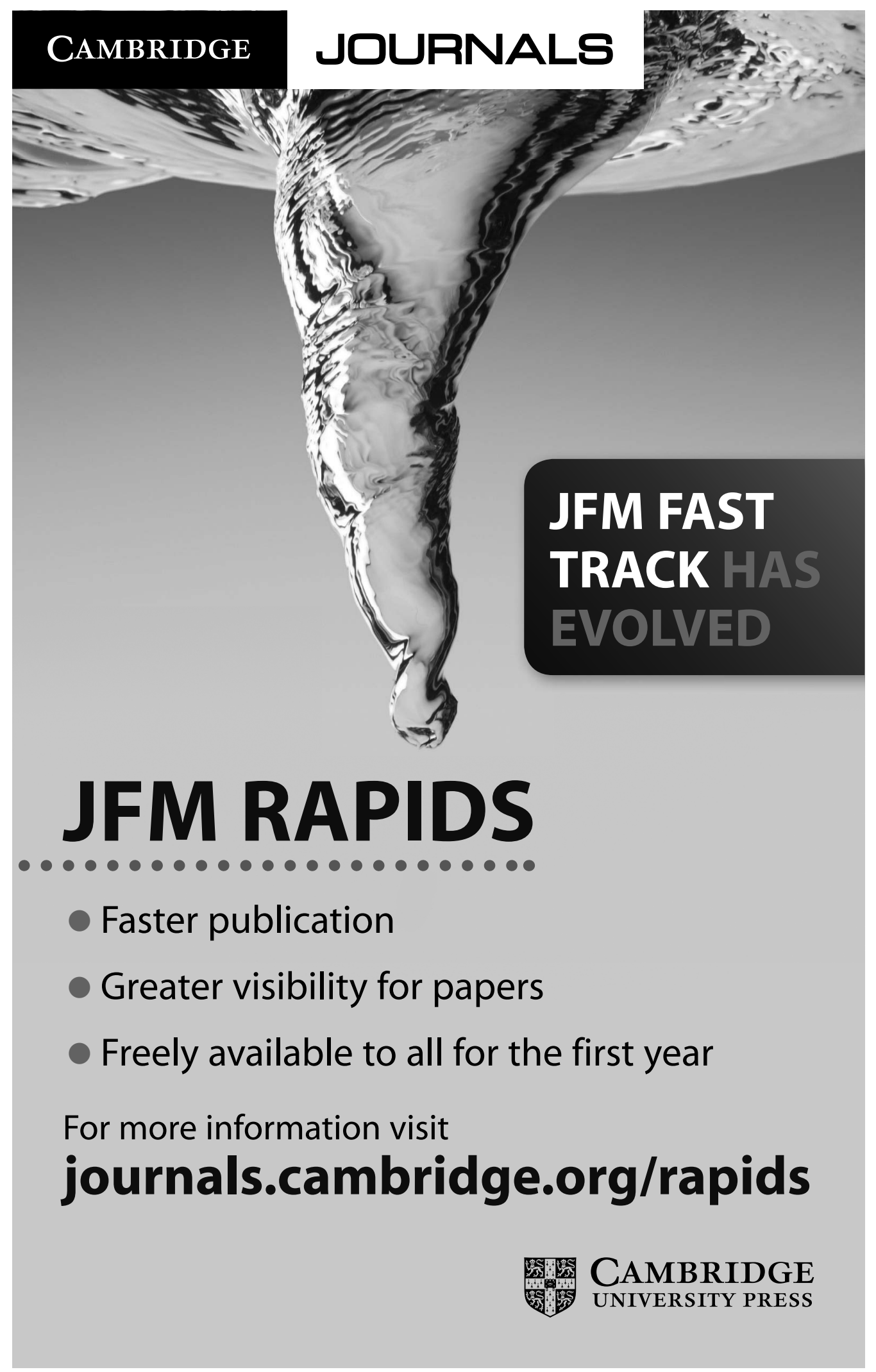




\section{CAMBRIDGE}

\section{JOURNALS}

\section{Proceedings of the Edinburgh Mathematical Society}

Published for The Edinburgh Mathematical Society

\section{Editorial Management}

The Secretary, ICMS, Edinburgh, UK

The Edinburgh Mathematical Society was founded in 1883 and over the years, has evolved into the principal society for the promotion of mathematics research in Scotland. The Society has published its Proceedings since 1884. This journal contains research papers on topics in a broad range of pure and applied mathematics, together with a number of topical book reviews.

\section{Price information}

is available at: http://journals.cambridge.org/pem

\section{Free email alerts}

Keep up-to-date with new material - sign up at http://journals.cambridge.org/pem-alerts

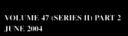

\section{Proceedings}

of the

Edinburgh

Mathematical

Society

CAMBRIDGE

Proceedings of the Edinburgh Mathematical Society is available online at: http://journals.cambridge.org/pem

To subscribe contact Customer Services

\section{in Cambridge:}

Phone +44 (0)1223 326070

$\mathrm{Fax}+44(0) 1223325150$

Email journals@cambridge.org

in New York:

Phone +1 (845) 3537500

Fax +1 (845) 3534141

Email

subscriptions_newyork@cambridge.org 


\section{CAMBRIDGE}

\section{JOURNALS}

\section{Glasgow Mathematical Journal}

Published for The Glasgow Mathematical Journal Trust

\section{Editor-in-Chief}

I. A. B. Strachan, University of Glasgow, UK

Glasgow Mathematical Journal publishes original research papers in any branch of pure and applied mathematics. An international journal, its policy is to feature a wide variety of research areas, which in recent issues have included ring theory, group theory, functional analysis, combinatorics, differential equations, differential geometry, number theory, algebraic topology, and the application of such methods in applied mathematics.

\section{Price information}

is available at: http://journals.cambridge.org/gmj

\section{Free email alerts}

Keep up-to-date with new material - sign up at http://journals.cambridge.org/gmj-alerts

To subscribe contact Customer Services

\section{in Cambridge:}

Phone +44 (0)1223 326070

Fax +44 (0)1223 325150

Email journals@cambridge.org

\section{in New York:}

Phone +1 (845) 3537500

Fax +1 (845) 3534141

Email

subscriptions_newyork@cambridge.org 


\section{CAMBRIDGE}

\section{JOURNALS}

\section{The European Physical Journal - Applied Physics}

Marketed and distributed on behalf of ÉDP Sciences

\section{Editor-in-Chief}

B. Drévillon, LPCIM, France

$E P J-A P$ is an international journal devoted to the promotion of the recent progresses in all fields of applied physics. The articles published in EPJ-AP span the whole spectrum of applied physics research including semiconductors, organic materials, thin films, nanotechnology, photonics, spintronics, magetism, plasma, energy generation transfer, metrology, fluids and microfluidics, biophysics and biosensors, surfaces and interfaces.

\section{Price information}

is available at: www.epjap.org

\section{Free email alerts \\ Keep up-to-date with new material - sign up at http://www.epjap.org/jap-alerts}

To subscribe contact Customer Services

\section{Americas:}

Phone +1 (845) 3537500

Fax +1 (845) 3534141

Email

subscriptions_newyork@cambridge.org

\section{Rest of world:}

Phone +44 (0)1223 326070

$\mathrm{Fax}+44(0) 1223325150$

Email journals@cambridge.org

\section{edpsciences}


554 Boundary-layer flow and bed shear stress under a solitary wave: revision

Y. S. Park, J. Verschaeve, G. K. Pedersen \& P. L.-F. Liu

\section{JFM Rapids (online only)}

$S$ R1 Instability of a gravity current within a soap film

R. E. Goldstein, H. E. Huppert,

H. K. Moffatt \& A. I. Pesci

$S$ indicates supplementary data or movies available online.
560 The planar X-junction flow: stability analysis and control - CORRIGENDUM

I. Lashgari, O. Tammisola, V. Citro, M. P. Juniper \& L. Brandt 
1 The planar X-junction flow: stability analysis and control

I. Lashgari, O. Tammisola, V. Citro, M. P. Juniper \& L. Brandt

29 Role of slipstream instability in formation of counter-rotating vortex rings ahead of a compressible vortex ring

C. L. Dora, T. Murugan, S. De \& D. Das

49 Electrophoresis of bubbles

\section{O. Schnitzer, I. Frankel \& E. Yariv}

80 Topographic control of stratified flows: upstream jets, blocking and isolating layers K. B. Winters \& L. Armi

104 Test of the anomalous scaling of passive temperature fluctuations in turbulent Rayleigh-Bénard convection with spatial inhomogeneity

X. He, X.-D. Shang \& P. Tong

$S 131$ Shear-imposed falling film

\section{A. Samanta}

150 Numerical simulation of sand waves in a turbulent open channel flow

\section{A. Khosronejad \& F. Sotiropoulos}

217 The influence of nonlinear bottom friction on the properties of decaying cyclonic and anticyclonic vortex structures in a shallow rotated fluid

S. V. Kostrykin, A. A. Khapaev \&

I. G. Yakushkin

$S 242$ Stratified shear flow: experiments in an inclined duct

C. R. Meyer \& P. F. Linden

254 Steady streaming in a two-dimensional box model of a passive cochlea

E. Edom, D. Obrist \& L. Kleiser

Contents continued on inside back cover.
279 A parametric study of the coalescence of liquid drops in a viscous gas

J. E. Sprittles \& Y. D. Shikhmurzaev

307 The generalized Onsager model for a binary gas mixture

\section{Kumaran \& S. Pradhan}

360 Effects of radiation in turbulent channel flow: analysis of coupled direct numerical simulations
R. Vicquelin, Y. F. Zhang, O. Gicquel \&
J. Taine

402 On grid-generated turbulence in the near- and far field regions

J. C. Isaza, R. Salazar \& Z. Warhaft

427 Trapped modes and scattering for oblique waves in a two-layer fluid

M. I. Romero Rodríguez \& P. Zhevandrov

448 Thermoacoustic instability - a dynamical system and time domain analysis

T. Sayadi, V. Le Chenadec, P. J. Schmid, F. Richecoeur \& M. Massot

472 Inertial wave dynamics in a rotating liquid metal

T. Vogt, D. Räbiger \& S. Eckert

499 Large-eddy simulation of turbulence and particle dispersion inside the canopy roughness sublayer

Y. Pan, M. Chamecki \& S. A. Isard

535 Viscous Marangoni migration of a drop in a Poiseuille flow at low surface Péclet numbers O. S. Pak, J. Feng \& H. A. Stone

553 Boundary layer flow and bed shear stress under a solitary wave - CORRIGENDUM P. L.-F. Liu, Y. S. Park \& E. A. Cowen 